\title{
Diagnóstico inmunohistoquímico de un caso de leishmaniosis visceral canina
}

\author{
Burna, A.N. ${ }^{1}$; Catuogno, M.S.'; Mirad, A. ; Maccio, O.A. ${ }^{2}$ \\ ${ }^{1}$ Cátedra de Patología General y Sistemática y ${ }^{2}$ Hospital de Clínica, Facultad de Ciencias Veterinarias, \\ Universidad Nacional del Nordeste UNNE, Sargento Cabral 2139, Corrientes (3400), Argentina. \\ E-mail: patgral@vet.unne.edu.ar.
}

\begin{abstract}
Resumen
Burna, A.N.; Catuogno, M.S.; Mirad, A.; Maccio, O.A.: Diagnóstico inmunohistoquímico de un caso de leishmaniosis visceral canina. Rev. vet. 23: 2, 144-146, 2012. En la leishmaniosis los cuadros clínicos, pese a su variabilidad y escasa especificidad, pueden orientar el diagnóstico siempre que se apoyen en una anamnesis exhaustiva que ofrezca datos epidemiológicos relevantes, como ser: el hábitat, tipo de actividad, tiempo de exposición al vector y otros. El diagnóstico parasitológico se basa en la observación del parasito en frotis o biopsias de material obtenido de bazo, médula ósea o nódulo linfático. Las técnicas determinantes son: reacción en cadena de la polimerasa (PCR), xenodiagnóstico (infección del flebótomo) e inmunohistoquímica. El objetivo de la presente comunicación fue reportar el diagnostico definitivo de un caso de leishmaniosis visceral canina mediante inmunohistoquimica. Dicha técnica reveló la presencia de amastigotes en todos los órganos de las cavidades abdominal y torácica, confirmando el diagnóstico de leishmaniosis visceral. Cabe destacar la observación de dicho parásito en el ovario del animal.
\end{abstract}

Palabras clave: perro, leishmaniosis visceral, inmunohistoquímica, diagnóstico.

\begin{abstract}
Burna, A.N.; Catuogno, M.S.; Mirad, A.; Maccio, O.A.: Immunohistochemical diagnosis of a case of canine visceral leishmaniosis. Rev. vet. 23: 2, 144-146, 2012. For the diagnosis of leishmaniosis clinical examinations, although highly variable and nonspecific, serves to guide the diagnosis, provided they are supported by a comprehensive anamnesis with relevant epidemiological data such as: habitat, exposure time to the vector, and geography. Parasitological diagnosis is based on observation of the parasite by smear or biopsy material obtained from spleen, bone marrow or lymph node. Determining techniques are polymerase chain reaction (PCR), xenodiagnosis (infection of phlebotomus) and immunohistochemistry. The aim of this paper was to report the final diagnosis by immunohistochemistry of a case of visceral leishmaniosis with characteristic signs and symptoms of the disease. The immunohistochemical study revealed the presence of leishmania amastigotes in all organs of the abdominal cavity and chest confirming the diagnosis of visceral leishmaniosis. It is worth mentioning the observation of the parasite in the ovary of the animal.
\end{abstract}

Key words: dog, visceral leishmaniosis, immunohistochemistry, diagnosis.

\section{INTRODUCCIÓN}

En la leishmaniosis los cuadros clínicos, aunque muy variables y poco específicos, sirven para orientar el diagnóstico, siempre y cuando se apoyen en una anamnesis exhaustiva que ofrezca datos epidemiológicos relevantes como ser: hábitat, tipo de actividad, tiempo de exposición al vector, zona geográfica, procedencia y otros ${ }^{5}$.

En zonas endémicas, un solo síntoma compatible con leishmaniosis habilita la realización de pruebas

Recibido: 23 abril 2012 / Aceptado: 3 julio 2012 diagnósticas específicas. Se considera "sospechoso" todo animal que proceda de una zona endémica o que haya permanecido en la misma durante el periodo de actividad del vector ${ }^{6}$.

El diagnóstico parasitológico de leishmaniosis se basa en la observación del agente etiológico. Esto se logra por examen directo, frotis, biopsia histopatológica o cultivo de material obtenido del bazo, médula ósea o nódulo linfático. La biopsia se usa muchas veces como método para el diagnóstico de las lesiones tegumentarias, sobre todo en sitios donde no hay facilidades para el cultivo del parásito. En algunos casos la histopatología por sí sola permite hacer el diagnóstico, al detectar 
los amastigotes. En otros, aunque las características de la reacción inflamatoria sugieren la presencia del parásito, su visualización es dificultosa ${ }^{7}$.

Los conceptos vertidos resaltan la necesidad de incorporar nuevas alternativas de diagnóstico, en particular para las lesiones de evolución crónica donde el parásito resulta difícilmente evidenciable ${ }^{2,3,8}$. Algunas de tales alternativas pueden provenir de la reacción en cadena de la polimerasa (PCR), xenodiagnóstico (infección del flebótomo transmisor) e inmunohistoquímica (motivo del presente estudio). Todas ellas constituyen pruebas determinantes ${ }^{1,4}$.

El objetivo de la presente comunicación fue reportar el caso clínico de un canino con síntomas y signos característicos de la enfermedad y su diagnóstico mediante inmunohistoquímica como método confirmatorio.

\section{MATERIAL Y MÉTODOS}

Una hembra Pit Bull de 8 meses de edad, nacida y criada en la ciudad de Clorinda, Provincia de Formosa (Argentina) fue trasladada a Corrientes y sometida a consulta particular por padecer dermatitis exfoliativa con agrandamiento de nódulos linfáticos. La sospecha

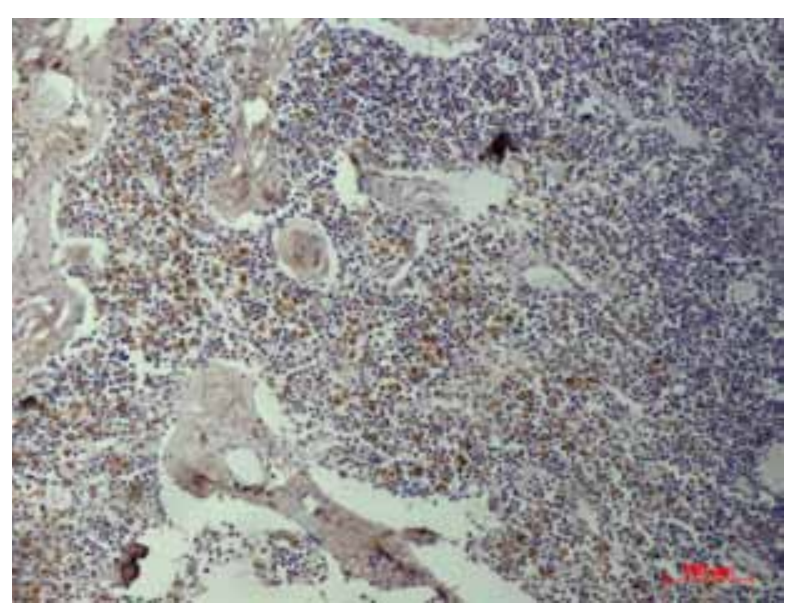

Figura 1. Nódulo linfático: amastigotes dentro de los macrófagos. Técnica de inmunohistoquímica, $40 \mathrm{X}$.

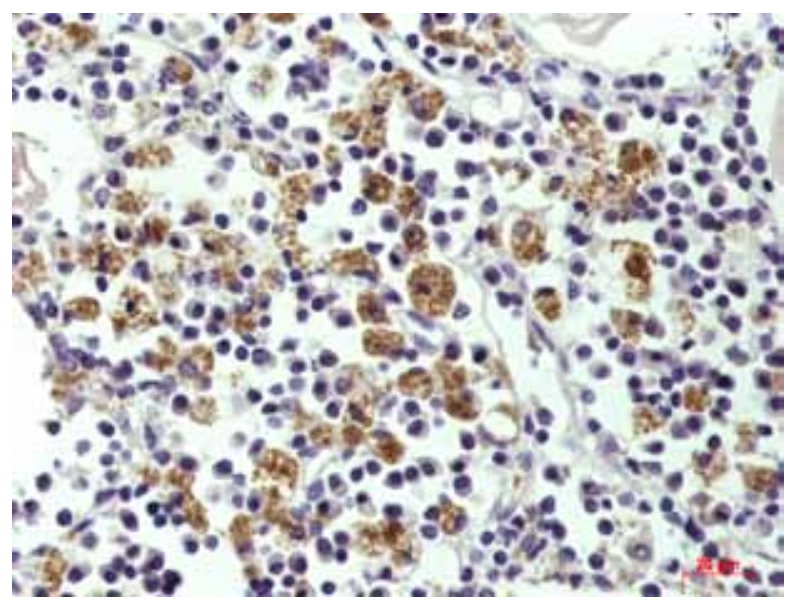

Figura 2. Bazo: observación de amastigotes de leishmania. Técnica de inmunohistoquímica, $10 \mathrm{X}$. de leishmaniosis se confirmó por diagnóstico serológico (test rK 39), específico para el tipo visceral.

Luego de la muerte del animal, se efectuó la necropsia en el Laboratorio de Anatomía Patológica de la Facultad de Ciencias Veterinarias de la UNNE, obteniéndose muestras de todos los órganos, las cuales fueron fijadas en formol bufferado al $10 \%$, incluidas en parafina, cortadas a 5 um y coloreadas con hematoxilina y eosina como prueba de rutina.

En la Facultad de Medicina de la Universidad de San Pablo (Brasil) se realizó la técnica de inmunohistoquímica utilizando un anticuerpo policlonal primario anti-leishmania producido en ratones. Muestras de órganos de las cavidades torácica y abdominal fueron incluidas en parafina sólida, cortadas con micrótomo (5 um) y montadas en portaobjetos con una solución de poly-L-lysine. Luego fueron desparafinadas, rehidratadas e inactivadas con peroxidasa endógena, tras lo cual fueron sucesivamente cubiertas con anticuerpos primarios y luego anticuerpos secundarios biotinilados. Posteriormente se trataron con estreptavidina-peroxidasa, se aplicó un cromógeno revelador del antígeno y por último se contrastó con hematoxilina para su ulterior montaje.

\section{RESULTADOS Y DISCUSIÓN}

La necropsia reveló la existencia de hepato y esplenomegalia, características de esta enfermedad. El estudio histopatológico evidenció lesiones compatibles con leishmaniosis visceral, aunque la presencia de amastigotes en el interior de los macrófagos solo fue observada escasamente en la piel ${ }^{3,7,8}$.

Los resultados de los análisis complementarios fueron positivos a la prueba de formogelificación y al diagnóstico con tira reactiva $r K 39$ Kala Azar Detec Canina, no obstante el examen parasitológico directo en frotis coloreados con Giemsa arrojó resultado negativo. Tampoco se pudieron observar parásitos en los extendidos de médula ósea ni de nódulos linfoides. En cambio, el examen mediante inmunohistoquímica reveló la presencia de amastigotes de leishmania en todos los órganos tanto de la cavidad abdominal como torácica (Figuras 1 y 2), incluyendo el ovario del animal

Se destaca la importancia de la inmunohistoquímica como técnica confirmatoria de dicha enfermedad debido a su especificidad ${ }^{1}$. Nuestro grupo de trabajo está abocado a la estandarización de dicha técnica para poder brindar un diagnóstico especifico de leishmaniosis.

\section{REFERENCIAS}

1. Alvar J, Cañavate $\mathbf{C}$, Molina $\mathbf{R}$, Moreno $\mathbf{J}$, Nieto $\mathbf{J}$. 2002. Canine leishmaniasis. Adv Parasit 57: 1-88.

2. Hendrichs L, Wright N. 1979. Diagnosis of cutaneous leishmaniasis by in vitro cultivation of saline aspirates in Schneider's Drosophila medium. Am J Trop Med Hyg 28: 962-964. 
3. Kerdel-Vargas F, Essenfeld-Yahr E. 1966. Histopatología de la leishmaniasis americana. Med Cut 3: 267-276.

4. Killick-Kendrick R. 1999. The biology and control of phlebotomine sandflies. Clin Dermatol 17: 279-289.

5. Koutinas A, Polizopulou ZS, Saridomichelakis MN, Argyriadis D, Fytianou A, Plevaraki K. 1999. Clinical considerations on canine visceral leishmaniosis in Greece: a retrospective study of 158 cases (1989-1996). J Am Ass Hosp Anim 35: 376-383.
6. Miró G, Fraile C. 1999. Leishmaniosis canina: revisión práctica. Rev Consult Dif Vet (España) 7: 63-74.

7. Thomburgh DB, Johnson CM, Elton NW. 1952. The histopathology of cutaneous leishmaniasis in Panamá. Trans R Soc Trop Med Hyg 46: 550-554

8. Weigle KA, Dávalos M, Heredia P, Molineros R, Saravia NG, D'Alessandro A.1987. Diagnosis of cutaneous and mucocutaneous leishmaniasis in Colombia: a comparison of seven methods. Am J Trop Med Hyg 36: 489-496. 